\title{
PERCEPÇÃO SOCIOAMBIENTAL DOS RESIDENTES DO IGARAPÉ SANTA \\ CRUZ NO MUNICÍPIO DE BREVES (PA): VIVÊNCIAS E DESAFIOS SOBRE A CAPTAÇÃO E USO DA ÁGUA
}

\author{
Manolo Cleiton Costa de Freitas ${ }^{1}$ \\ Cristiane Alves Barreto ${ }^{2}$ \\ Gabriela Barbosa dos Santos ${ }^{3}$ \\ Ana Carolina Gomes de Albuquerque de Freitas ${ }^{4}$ \\ Nívia Magalhães da Silva Freitas 5
}

Resumo: O crescimento urbano desordenado iniciou-se na segunda metade do século 20, em meados desse século o Brasil tornou-se um país urbano, ou seja, mais de $50 \%$ de sua população passou a residir nas cidades. É neste contexto que ocorre o processo de expansão urbana de Breves-PA, em que ao longo dos anos houve maior aglome-ração populacional, nas zonas periféricas, como é o caso da área entorno ao igarapé Santa Cruz, acarretando cenários de problemas ambientais de várias ordens. Diante destes cenários, o presente estudo teve como objetivo identificar a situação ambiental do igarapé Santa Cruz, bem como realizar um breve estudo sobre a percepção dos residentes quanto ao meio ambiente, à captação e utilização da água do igarapé.

Palavras-chave: Amazônia Marajoara; Percepção Ambiental; Residentes Ribeirinhos.

\footnotetext{
1 Universidade Federal do Pará. E-mail: manolo@ufpa.br, Link para o Lattes: http://lattes.cnpq.br/7328679372733759

2 Universidade Federal do Pará. E-mail: cristiane.barreto@breves.ufpa.br, Link para o Lattes: http://lattes.cnpq.br/0312725067808872

${ }^{3}$ Universidade Federal do Pará. E-mail: gabrielabarbosagb143@gmail.com, Link para o Lattes: http://lattes.cnpq.br/6240410193666866

${ }^{4}$ Universidade Federal do Sul e Sudeste do Pará. E-mail: albuquerqueacg@gmail.com, Link para o Lattes: http://lattes.cnpq.br/5529257725425310

${ }^{5}$ Universidade Federal do Pará. E-mail: nivia.bio2015@gmail.com,

Link para o Lattes: http://lattes.cnpq.br/1600459523697661
} 
Abstract: The disorderly urban growth started in the second half of the 20th century, in the middle of that century Brazil became an urban country, that is, more than $50 \%$ of its population started to live in cities. It is in this context that the urban expansion process of Breves-PA occurs, in which, over the years, there was greater population agglomeration, in the peripheral zones, as is the case of the area surrounding the Santa Cruz stream, resulting in scenarios of environmental problems of various orders. Given these scenarios, the present study aimed to identify the environmental situation of the Santa Cruz stream, as well as to conduct a brief study on the residents' perception of the environment, the capture and use of the stream water.

Keywords: Amazônia Marajoara; Environmental Perception; Riverside Residents.

\section{Introdução}

Desde a antiguidade, o homem se compreende como um ser racional e considera a natureza e seus recursos como um meio para obtenção de seu bemestar, porém ao longo dos séculos, este cenário vem se tornando um sério agravante, pois o uso continuo e exagerado dos recursos naturais, resulta em diversos danos ambientais, trazendo à tona, a depredação do meio ambiente e acumulando assim efeitos nocivos ao seu comportamento. A partir disso, a crise ambiental vem sendo intensificada pela relação população-recursos. Para muitos ambientalistas a explosão demográfica é uma das principais causas da degradação do meio ambiente (CUNHA; AUGUSTIN, 2014).

É neste contexto, que o Município de Breves-PA, apesar de ser uma cidade de pequeno porte, teve um crescimento desordenado nas áreas urbanizadas, provocando assim à degradação ambiental do meio natural, devido ao seu expressivo crescimento demográfico e territorial nos últimos 30 anos. Este município está localizado no Estado do Pará, mais precisamente na Amazônia Marajoara. Pertence geograficamente a uma região com recursos hídricos nos seus diversos limítrofes, uma região de "furos", leitos de rios e igarapés - muitos desses leitos adentram a cidade, como é o caso do igarapé Santa Cruz.

Segundo Valente (2017, p.2), compreende-se que a hidrografia do Município de Breves é:

[...] bastante complexa, representada pelo emaranhado de furos, paranás e igarapés. O mais importante é o rio Jacaré Grande, na porção centro-norte do município. Este rio se intercomunica com vários furos e igarapés em todas as direções, sendo o maior deles - o Furo dos Macacos - que vai até o sul do município, interligando-se com outros furos, inclusive o rio Breves, onde está a sede do município. $\mathrm{O}$ rio Jacaré Grande desagua na central do Vieira Grande, no norte do município e esse, por sua vez, se comunica com o rio Amazonas. Recebe o rio Jacaré

revista brasileira educação ambiental 
Grande um tributário importante que é o rio Araumã, limite natural entre Breves, Afuá e Anajás.

Na década de 1980 o Igarapé Santa Cruz era pouco habitado, servia de ligação marítima entre as comunidades ribeirinhas que traziam seus produtos agrícolas para venderem no comércio local, também era utilizado como área de lazer por moradores que residiam nas proximidades. No entanto, o crescimento urbano e a falta de planejamento habitacional, forçou a população a construir suas casas as margens do igarapé, comprometendo assim sua paisagem natural e trazendo sérios problemas de poluição ambiental para ele, bem como para as pessoas que habitam e utilizam sua água para diversas atividades domésticas.

Os problemas mais visíveis no igarapé Santa Cruz são o despejo de lixo de diversos tipos como exemplos, lixo doméstico, cadáveres de animais, além de construções inadequadas de sanitários as suas margens, dentre outros. Portanto, estes problemas potencializam um sério risco a saúde da população, como o aumento de doenças de veiculação hídrica.

Embora o município esteja cercado por água, a sociedade brevense ao longo dos anos vem sofrendo sérios problemas com a falta de água potável. $A$ empresa Companhia de Saneamento do Pará (COSANPA), que é a responsável pelo abastecimento de água na cidade, não consegue contemplar todo o contingente urbano, levando os moradores a buscarem outros meios para a obtenção de água. Este fato leva os residentes das margens do igarapé Santa Cruz, a utilizarem da água do igarapé para diversos fins.

A partir da necessidade de uma melhor compreensão acerca das condições socioambientais dos residentes das margens do igarapé Santa Cruz, foi proposto e, sequencialmente, aprovado em edital da Pró-Reitoria de Extensão (PROEX) da Universidade Federal do Pará, um projeto de extensão intitulado: "Educação Socioambiental no Igarapé Santa Cruz no Município de Breves e Levantamento de Possíveis Ações de Intervenção Socioambiental', onde fosse possível introduzir discentes dos cursos de Ciências Naturais e de especialização em Ensino de Ciências na Contemporaneidade, ambos da faculdade de Ciências Naturais do Campus Universitário do Marajó-Breves. O objetivo da introdução dos discente foi para fazer com que estes pudessem debater sobre os principais problemas ambientais enfrentados pela comunidade ribeirinha do igarapé e expandir esse debate para os níveis local, regional e global, ao passo que fossem evoluindo criticamente sobre o assunto.

Diante do exposto, pretendeu-se com este estudo investigar a situação socioambiental dos residentes das margens do igarapé Santa Cruz, bem como a realização de um breve estudo sobre a percepção destes, quanto à captação de água para utilização em diversas atividades domésticas. 


\section{Referencial Teórico}

\section{Explosão Demográfica Desordenada}

A expansão da espécie humana, desde seu surgimento, sempre foi perpetuada através da procriação. Porém, há relatos históricos que denotam que o homem até o período de 8.000 a.C., não havia se expandido tão numerosamente, quanto nos dias atuais. No período em questão, surgiu à agricultura, sendo que a população mundial era composta de aproximadamente dez milhões de habitantes. O desenvolvimento das técnicas de agricultura, permitiram que 0 homem se agrupasse em comunidades e a ser descaracterizado como nômade, este fato fez com que houvesse um processo reprodutivo maior. Mas foi durante a revolução industrial, datada entre os séculos XVII e XVIII, que a população humana passou de trezentos milhões para oitocentos milhões, estes números são toleráveis, levando em consideração mais de mil e setecentos anos (GEWEHR, 2006).

O processo de crescimento populacional, descrito no período acima, é explanado no trabalho de Jacquard (1998, p.64), que esclarece:

[...] no ano 1000, ainda existem 250 milhões de homens. Depois, começa uma fase de crescimento lento: entre 1200 e 1500, atinge o patamar de 400 milhões, e esse número se mantém. Mas a partir de 1500, manifesta-se uma aceleração, provocada pelos progressos da higiene e da medicina. Em 1600, 580 milhões de homens; em 1700, 770 milhões; em 1800, 900 milhões. O primeiro bilhão é superado por volta de 1820 , e o segundo, meio século mais tarde, aproximadamente em 1925.

Tardiamente, o Brasil tornou-se um país urbano, este fato foi acentuado a partir da segunda metade do século XX, quando mais de $50 \%$ de sua população passou a migrar para as cidades e lá fixar residência. Em meados dos anos 50 , do século passado, houve um acelerado processo de urbanização no Brasil, associado a intensificação do processo de industrialização no país, marcando a partir de 1956, um período, como relata Miranda (2008), da "política desenvolvimentista" do governo Juscelino Kubitschek.

Polycarpo et al. (2018, p.2) esclarece ainda que:

O desenvolvimento que ocorreu no Brasil como fruto de políticas desenvolvimentistas a qualquer custo, gerou o crescimento acelerados das cidades brasileiras, cujo resultado tem sido uma configuração heterogênea destas, devido possibilitar 0 desenvolvimento de espaços urbanos adequados, mas também se caracterizar pela dominante pobreza urbana, onde a exclusão social e 0 desordenamento territorial têm ocasionado significativa mudança na sua estrutura interna, formação de anéis periféricos e expansão da região metropolitana. 
A configuração apontada, cria problemas intensos para a gestão urbana, sendo estes manifestados em ocupações irregulares, assentamentos subnormais em situação fundiária não regularizada, sem acesso a uma infraestrutura urbana adequada, muitas vezes sem condições de habitação digna. A situação relatada acima fica melhor exemplifica por Martins, (2012, p.10):

Como resultado desse e outros processos (e.g., industrialização das cidades) tem-se a poluição do ar e das águas, o lançamento de esgoto a céu aberto, a favelização, a ocupação de encostas e áreas de risco (OLIVEIRA, 2009), que por sua vez geram erosões do solo, enchentes, desabamentos, desmatamento e poluição dos mananciais de abastecimento e do ar, afetando assim o conjunto urbano e em especial as áreas ocupadas pela população de baixa renda.

\section{Consequências da explosão demográfica mundial sobre o meio ambiente}

As consequências do crescimento populacional já estão sendo experimentadas atualmente pela humanidade e sobretudo pela natureza. $O$ crescimento demográfico atingiu sobretudo o ambiente natural. Pois o homem por onde passa destrói e polui o meio ambiente (CORSON, 2002).

$\mathrm{O}$ crescimento das cidades e o aumento populacional acarretaram no aumento das catástrofes ambientais, além de representarem um acréscimo nos níveis de consumo, acabam por desencadear problemas de suma importância, principalmente no que diz respeito à produção de resíduos orgânicos e inorgânicos, revelando a problemática do lixo e seu alto impacto sobre o meio ambiente.

$\mathrm{O}$ aumento do lixo urbano, representado pelo crescimento das cidades, acaba por tornar a questão dos resíduos como um dos problemas ambientais mais alarmantes da atualidade. Nesse sentido, Scarlato e Pontin (2001) esclarecem que:

O lixo urbano é, provavelmente, um dos mais sérios problemas ambientais da atualidade - pois tudo aquilo que é introduzido em um sistema de fluxo, depois de processado, mais cedo ou mais tarde sai sob a forma de materiais secundários (subprodutos).

A formação de "lixões", provenientes da deposição de lixo próximo as grandes cidades, é muito mais veloz que a gestão de resíduos sólidos, realizada pelo Poder Público, que se mostra ineficaz frente ao problema do lixo urbano. Um dos fatos da ineficácia, está relacionado a ausência de estrutura física, revelando uma das realidades negativas em termos de meio ambiente, que é a proliferação de doenças (GEWEHR, 2006). Em relação a ineficaz gestão dos resíduos sólidos, Gouveia (2012, p. 1505), esclarece que: 
A decomposição da matéria orgânica presente no lixo resulta na formação de um líquido de cor escura, o chorume, que pode contaminar o solo e as águas superficiais ou subterrâneas pela contaminação do lençol freático. Pode ocorrer também a formação de gases tóxicos, asfixiantes e explosivos que se acumulam no subsolo ou são lançados na atmosfera.

Segundo Mucelin e Bellini (2008, p. 113):

A problemática ambiental gerada pelo lixo é de difícil solução e a maior parte das cidades brasileiras apresenta um serviço de coleta que não prevê a segregação dos resíduos na fonte (IBGE, 2006). Nessas cidades é comum observarmos hábitos de disposição final inadequados de lixo. Materiais sem utilidade se amontoam indiscriminada e desordenadamente, muitas vezes em locais indevidos como lotes baldios, margens de estradas, fundos de vale e margens de lagos e rios.

A problemática acima, transcende as cidades, sendo muitas vezes percebidas em comunidade afastadas dos centros urbanos.

Um dado alarmante, obtido no ano de 1989, menciona que foram geradas cerca de 100 mil toneladas de lixo residencial e comercial por dia, e três anos mais tarde o mesmo estudo foi realizado e revelou que houve um aumento em 57 mil toneladas por dia. Esses dados são resultados da Pesquisa Nacional de Saneamento Básico (PNSB), realizada no Brasil. Observou-se ainda que $20 \%$ da população não contavam com serviços regulares de coleta (SANTOS et al. 2010).

Gouveia (2012) reforça que dentre as formas de deposição de resíduos sólidos, a que mais potencializa o risco a saúde humana é a deposição realizada próximo a cursos d'água. Imagina-se que esta deposição é realizada por pessoas que ignoram ou desconhecem o impacto ambiental ocasionado. Como prováveis consequências, os resíduos podem se acumular às margens ou no fundo dos rios. O acúmulo pode ser potencializado quando chove. Muitas vezes, podem ser ingeridos por animais.

Ribeiro e Rooke (2010), relatam que segundo a Organização Mundial da Saúde (OMS) "grande parte de todas as doenças que se alastram nos países em desenvolvimento são provenientes da água de má qualidade. A água contaminada pode prejudicar a saúde das pessoas" a contaminação pode ocorrer "através da ingestão direta, na ingestão de alimentos, pelo seu uso na higiene pessoal e no lazer, na agricultura, na indústria" dentre outros.

Outro problema que requer uma atenção redobrada são as doenças relacionadas com as fezes. Observada a existência de coliformes fecais em um meio, isso sinaliza eminente contaminação fecal. Identificada a presença, na água, de bactérias do grupo coliforme, infere-se que esta água, está 
contaminada por fezes. Este grupo pode ser encontrado no solo, em alimentos, etc. Uma das causas mais prováveis da contaminação, seja, devido a animais utilizarem rio, lagos, córregos, dentre outros, como local de dessedentação. Outra causa, pode ser por esgotos sanitários que são lançados diretamente nestes locais, inativando o consumo da água (RIBEIRO; ROOKE, 2010).

Para Gewehr (2006):

Certamente que um dos grandes problemas das cidades atualmente está justamente em controlar dois aspectos cruciais desse processo que desencadeia grandes impactos ambientais: de um lado o crescimento demográfico desordenado e, de outro, a grande produção de resíduos, causadores de inúmeros danos ambientais e fatores de risco à saúde pública.

Tentar solucionar de forma concomitante os dois aspectos que mais potencializam os danos ao meio ambiente, parece algo inalcançável, pois seria necessário aplicar um plano de desenvolvimento sustentável ás cidades. O que é algo praticamente impossível, devido ao crescimento desordenado das cidades, onde não são respeitados os planos diretores, de modo que tal crescimento, comina no aparecimento de favelas em regiões ribeirinhas, deixando evidente o descaso com o meio ambiente. Alguns dos problemas mais marcantes são: o desmatamento, a poluição de rios e nascentes naturais, contaminação biológica das águas, dentre outros, causando grandes impactos ao ambiente natural (GEWEHR, 2006).

\section{A importância da educação ambiental na sociedade}

Em nome da chamada modernização das cidades, nos últimos séculos, a raça humana tem revelado um comportamento predatório sobre o meio ambiente. Este comportamento surgi mais efetivamente com o sistema capitalista que vê a natureza como fonte inesgotável de recursos, devendo servir as necessidades humanas para alcançar este sistema (REIS; SANTOS, 2015). Para Barbosa (2004), o rápido desenvolvimento científico e tecnológico culminou em perdas irreparáveis ao meio ambiente. Apesar do breve aparecimento do homem na Terra, se comparada a formação da mesma, este provocou alterações em vários ecossistemas, sendo que as alterações alcançaram a própria relação social.

As alterações, mencionadas anteriormente, têm posto em xeque a qualidade de vida de várias populações, como por exemplo, alterações na qualidade da água de muitos sistemas. Também, observa-se modificações na qualidade do ar. Alterações ecológicas ligadas ao desmatamento, queimadas, poluição de mares, rios e lagos, acarretam na morte de inúmeras espécies de animais (MENDONÇA, 2005).

Segundo a literatura, a primeira grande catástrofe ambiental aconteceu em Londres em 1952, quando o ar densamente poluído provocou a morte de 
1.600 pessoas, desencadeando o processo de sensibilização sobre a qualidade ambiental na Inglaterra, e culminando com a aprovação da Lei de Ar Puro pelo Parlamento, em 1956. Esse fato desencadeou uma série de discussões em outros países, catalisando o surgimento do ambientalíssimo nos Estados Unidos a partir de 1960 (DIAS, 2004).

Segundo Leff (2006), as ações do homem sobre a natureza vêm desencadeando uma crise ambiental que mostra a irracionalidade ecológica dos padrões dominantes de produção e de consumo e marcava os limites do crescimento econômico (LEFF, 2006, apud ZANIRATO, 2008).

É vital a iniciativa de ações que encontrem soluções para os problemas ambientais. Estas soluções devem causar imediatas mudanças na mentalidade da sociedade humana, pois assim minimizaria a falta de cuidado com o meio ambiente. Uma das iniciativas que pode contribuir, se não solucionar a problemática ambiental é a Educação Ambiental - EA (SANTOS et al. 2012).

Diante das ações e atitudes praticadas pelo homem, a EA desponta como importante ferramenta de intervenção. Segundo Merico (2001) apud Pessoa; Braga (2010), "A educação ambiental tem como objetivo transformar-se em filosofia de vida instigando o ser humano a atitudes que conduzam à sustentabilidade do meio ambiente".

De acordo com o trabalho realizado por Sato (2004), pode-se ler que a inicial definição sobre Educação Ambiental data do início da década de setenta (1971), proposta pela Internacional Union for the Conservation of Nature (União Internacional pela Conservação da Natureza), onde as definições e os conceitos estabelecidos foram ampliados, mais tarde, durante a Conferência de Estocolmo e, posteriormente, pela Conferência de Tbilisi realizada na Geórgia.

De acordo com a Lei № 6.938 de 1981 que instituiu a Política Nacional de Meio Ambiente (Art. $2^{\circ}, \mathrm{X}$ ), todos têm direito ao meio ambiente ecologicamente equilibrado, bem de uso comum do povo e essencial à sadia qualidade de vida, impondo-se ao Poder Público e a coletividade o dever de defendê-lo e preservá-lo para as presentes e futuras gerações (Art. 225, caput).

Segundo Barbieri (2004), a Conferência das Nações Unidas para o Meio Ambiente Humano realizada em Estocolmo em 1972, foi um marco para o início da discussão sobre Educação Ambiental, onde na referida conferência foi ressublinhada a urgente necessidade de serem criados novos instrumentos que fossem capazes de jogar luz nos problemas ambientais. O que compete a Resolução 96 da Conferência de Estocolmo a EA deve ser de caráter interdisciplinar com a finalidade de formar seres humanos aptos a viverem em harmonia com o meio ambiente. Para implementação desta Resolução, foi necessária a realização do Seminário Internacional sobre Educação Ambiental em 1975, proposto pela UNESCO e pela PNUMA. No mencionado seminário foi aprovada a Carta de Belgrado, onde pode-se ler os elementos básicos para se estabelecer um programa voltado para EA em diferentes níveis, nacional, regional ou local, cujo os objetivos preconizados são: 
1. Conscientização: contribuir para que indivíduos e grupos adquiram consciência e sensibilidade em relação ao meio ambiente como um todo e quanto aos problemas relacionados com ele; 2. Conhecimento: propiciar uma compreensão básica sobre o meio ambiente, principalmente quanto às influências do ser humano e de suas atividades; 3. Atitudes: propiciar a aquisição de valores e motivação para induzir uma participação ativa na proteção ao meio ambiente e na resolução dos problemas ambientais; 4. Habilidades: proporcionar condições para que os indivíduos e grupos sociais adquiram as habilidades necessárias a essa participação ativa; 5. Capacidade de avaliação: estimular a avaliação das providências efetivamente tomadas em relação ao meio ambiente e aos programas de educação ambiental; 6. Participação: contribuir para que os indivíduos e grupos desenvolvam o senso de responsabilidade e de urgência com respeito às questões ambientais. Barbieri (2004, p. 923).

A ocupação humana em ambientes urbanos mais saudáveis requer do cidadão a condição de ser agente principal no processo de interação com o meio. O ser humano precisa estimular a percepção e se compreender como um constituinte da natureza e não como um ser a parte. Esta forma de compreensão pressupõe melhorar as condições ambientais, modificando formas de uso e manutenção do lugar onde habita, pela fixação de hábitos culturais mais saudáveis.

\section{Objetivos e métodos}

É importante ressalta que o presente estudo faz parte de um projeto de extensão, onde se caracteriza por várias atividades desenvolvidas com caráter interdisciplinar, envolvendo diversas áreas do conhecimento técnico-científico e de saber popular, onde se permite a construção de uma relação entre as diversas formas de apreensão da realidade social. O projeto foi implementado na cidade de Breves-PA, na área entorno ao igarapé Santa Cruz (Figura 1), abrangendo os bairros Castanheira, Santa Cruz e Jardim Tropical no qual se pretendeu identificar a situação ambiental do igarapé, bem como fazer um estudo em relação à percepção dos ribeirinhos quanto à captação de água para utilização em atividades domésticas. 


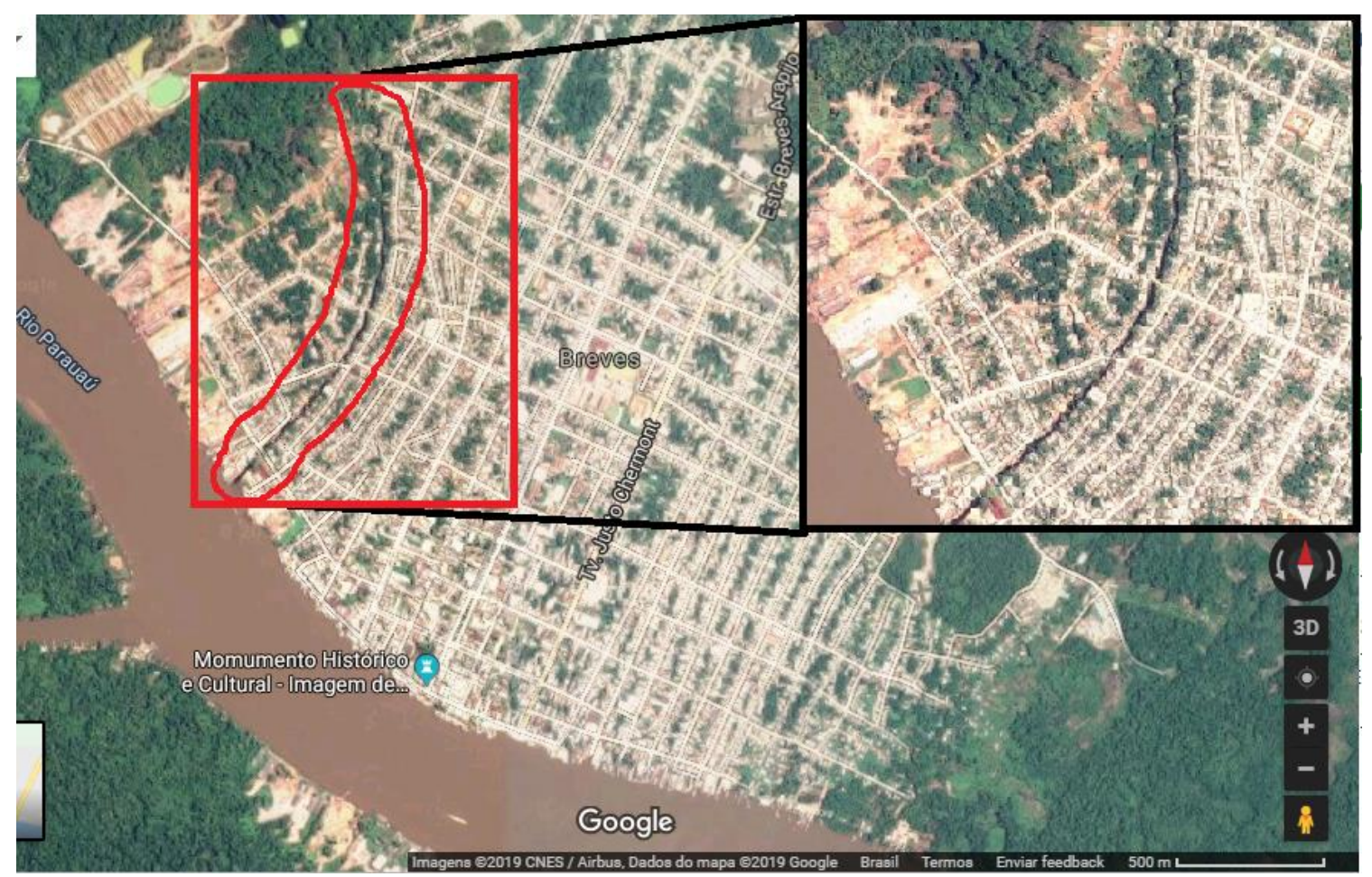

Figura 1: Local de desenvolvimento da pesquisa.

Fonte: Adaptada de mapa google, 2019.

A metodologia é de natureza participativa, posto que, essa técnica capacita os atores, implicando-os na construção do projeto e no seu desenrolar (THIOLLENT, 2000). Nesta perspectiva a instrumentalização para o trabalho extensionista, pode se dá com base ao estímulo à cooperação, num compromisso de solidariedade entre os vários atores sociais envolvidos no processo.

A pesquisa foi de cunho qualitativo e quantitativo, de modo que possibilitou melhor compreensão do cenário estudado.

Para a coleta de dados foi aplicado um questionário a moradores que residem às margens do igarapé Santa Cruz, um total de 84 famílias que concordaram em participar do estudo. Foi excluído deste estudo famílias cujas casas se encontravam fechadas ou ainda na ausência de um responsável de maior idade nas referidas residências. O questionário aplicado aos participantes continha um total de 19 perguntas fechadas. Neste sentido associa-se a uma postura ética que visa um tipo de emancipação, envolvendo a discussão e a autonomia dos participantes na "perspectiva de uma extensão ativa, participativa, capaz de contribuir para estudos, experimentações ou ações coletivas sobre questões sociais e educacionais". 


\section{Resultados}

Baseado nos dados coletados com a aplicação de questionário, observação, estruturou-se a elaboração deste estudo, em que se aborda a real situação do igarapé Santa Cruz e à percepção dos ribeirinhos quanto à captação de água para utilização em diversas atividades. O contexto desta análise está associado aos aspectos sociais dos residentes/ribeirinhos que habitam as margens do igarapé Santa Cruz, impactos ambientais, organização do espaço urbano, poluição das águas, coleta de lixo e outros.

A área pesquisada soma um total de 455 pessoas distribuídas em 84 famílias, que são formadas em sua maioria por moradores com idade maior/igual a 18 anos, marcando assim a presença de moradores antigos que acompanharam todo processo de transformação do igarapé Santa Cruz. Segundo relatos, muitos indivíduos vieram do interior (zona rural) do Município de Breves/PA e outras cidades vizinhas em busca de emprego, escola e melhores condições de vida, levando-se em consideração as constantes dificuldades sofridas em decorrência das precárias condições de subsistência no local de origem. A quantidade de crianças e adolescentes é bem menor que a quantidade de adultos presentes nesse contexto social.

A maioria dos entrevistados possui renda familiar de um salário mínimo, isto se atribui pelo fato de não possuir um emprego fixo, sobrevivem da venda de produtos diversos ou de "bicos" - um trabalho rápido, de período curto de tempo com pagamento à vista, sem vínculo empregatício -, ou ainda de auxílios do governo federal como bolsa família, aposentadoria e auxílio doença. Em relação a complementação de renda, entre os principais auxílios do governo federal, o que mais se destaca é o bolsa família, onde, cerca $80 \%$ dos indivíduos recebe este benefício.

Os moradores da área não dispõem de água encanada, uma vez que a COSANPA, não consegue realizar a distribuição de água potável para todos os bairros do município, devido a problemas principalmente relacionados com a infraestrutura. Após análise sobre a obtenção de água para o preparo de alimentos, percebeu-se que todos os moradores não dispõem de água encanada, forçando-os a recorrer de outros meios para a obtenção deste recurso. Pôde-se observar que $95 \%$ dos pesquisados busca outros meios de captação da água para o preparo dos alimentos, entre eles destaca-se a água do Rio Parauaú (Figura 2) 


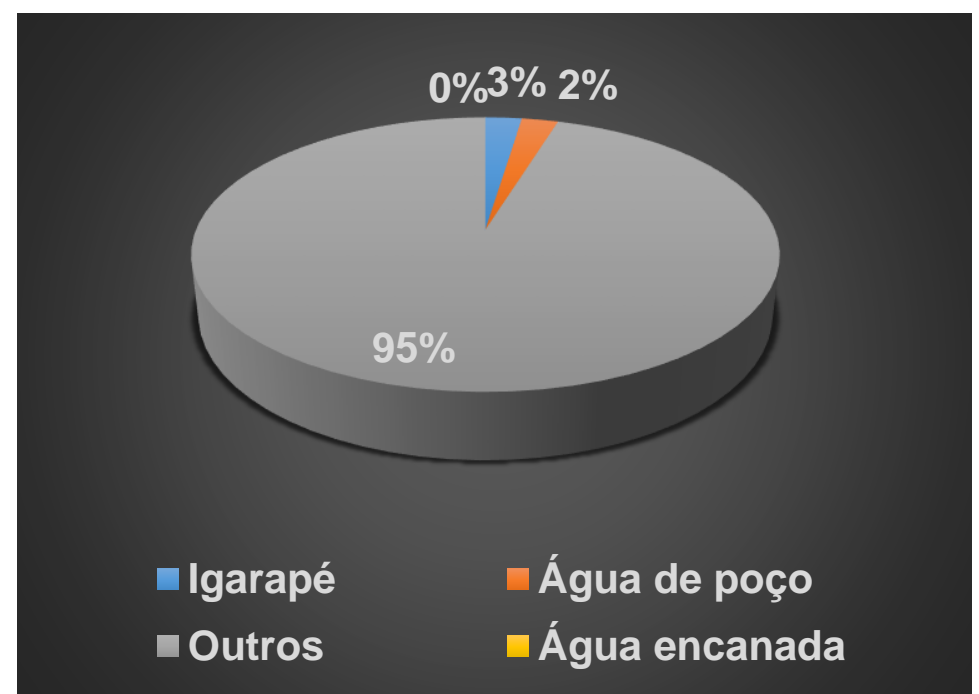

Figura 2: Obtenção da água para o preparo dos alimentos Fonte: Dados da pesquisa (2018).

A obtenção de água do Rio Parauaú é realizada pela simples imersão de baldes no meio do rio, sendo que o acesso ao local de coleta é feito através de pequenas embarcações denominadas de rabetas (Figura 3).



Figura 3: Embarcação utilizada pelos residentes (rabeta). Fonte: Dados produzidos pelo autor.

A água obtida de poços artesianos geralmente chega às residências por meio de carros-pipa ou ainda são adquiridas por meio de compra de baldes com água. Algumas pessoas (carroceiros, Figura 4) fazem a captação da água em poços artesianos de algumas escolas da cidade, próximas ao igarapé, e saem pelas ruas vendendo. Segundo informações de residentes, o balde com água custa $R \$ 2,00$ (dois reais). 


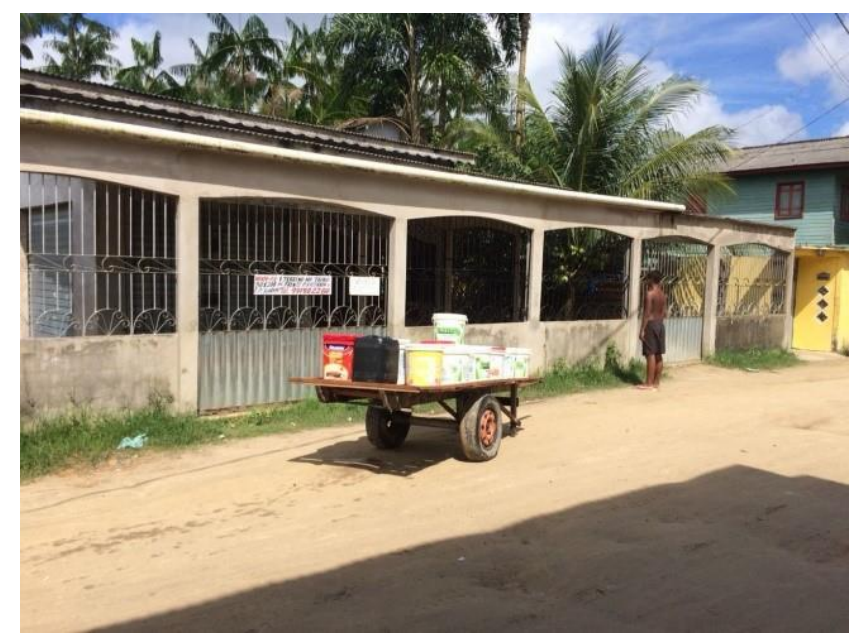

Figura 4: Vendas de baldes com água. Fonte: Dados da pesquisa (2018).

Quanto à fonte de obtenção de água para consumo próprio (para beber), a maioria dos pesquisados, cerca de $77 \%$, afirmou que utiliza outros meios para a obtenção de água. Cerca de $22 \%$ utiliza água de poço, que geralmente chega às residências por meio de carros-pipa ou ainda comprada de pessoas que fazem a venda em carros de mão. Como relatado anteriormente $0 \%$ dos entrevistados não dispõe de água encana, uma vez que a COSANPA no município não consegue fazer a distribuição de água para todos os bairros devido a problemas de infraestrutura. Os dados percentuais estão ilustrados em gráfico presente na Figura 5.

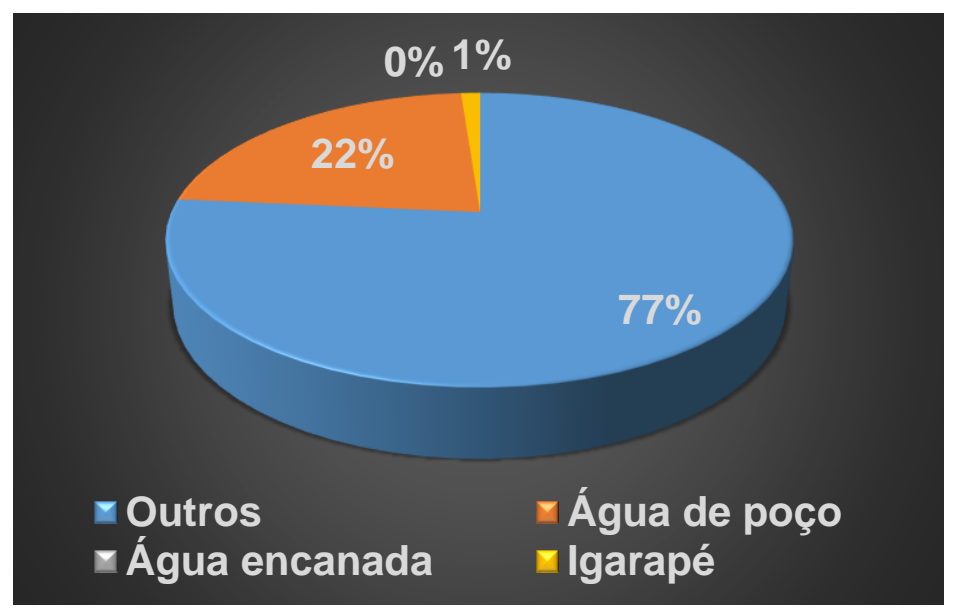

Figura 5: Obtenção de água para beber.

Fonte: Dados da pesquisa (2018).

Apenas $1 \%$ dos pesquisados afirmou utilizar a água do igarapé Santa Cruz, para consumo direto, consumo este que, provavelmente, compromete a saúde destes, por se tratar de água, certamente, contaminada. Na Figura 6 , pode-se observar um residente captando água do igarapé. A contaminação do 
igarapé Santa Cruz, se dá em virtude de sanitários construídos as suas margens, bem como deposição de lixos despejados pela própria população.

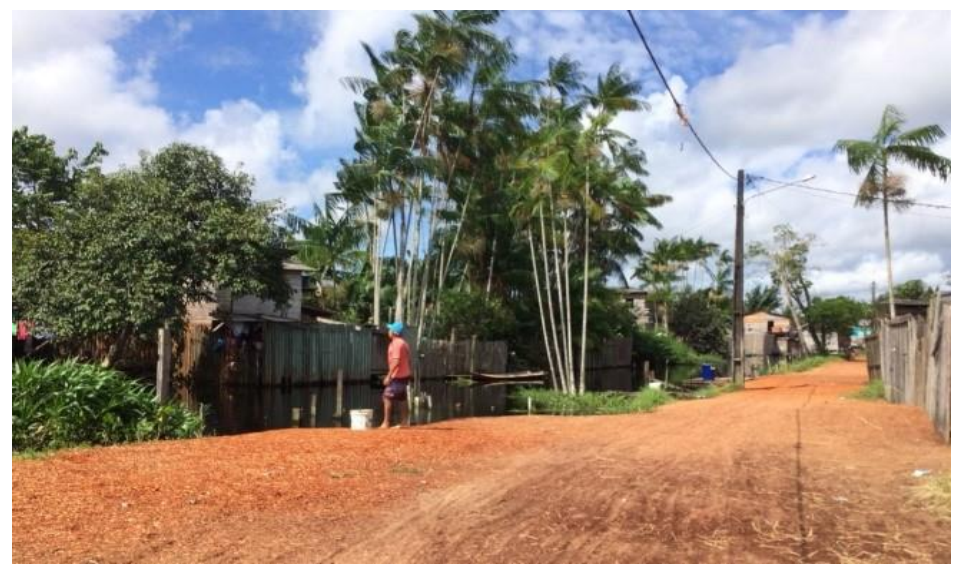

Imagem 6: Captação da água do igarapé. Fonte: Dados da pesquisa (2018).

Foi possível observar que a maioria dos entrevistados (54\%) faz corretamente o tratamento da água antes de consumi-la e utilizam como principal fonte de tratamento hipoclorito, água sanitária, fervura da água e outros. Os que não julgam ser necessário o tratamento de água totaliza $46 \%$ dos pesquisados (Figura 7).

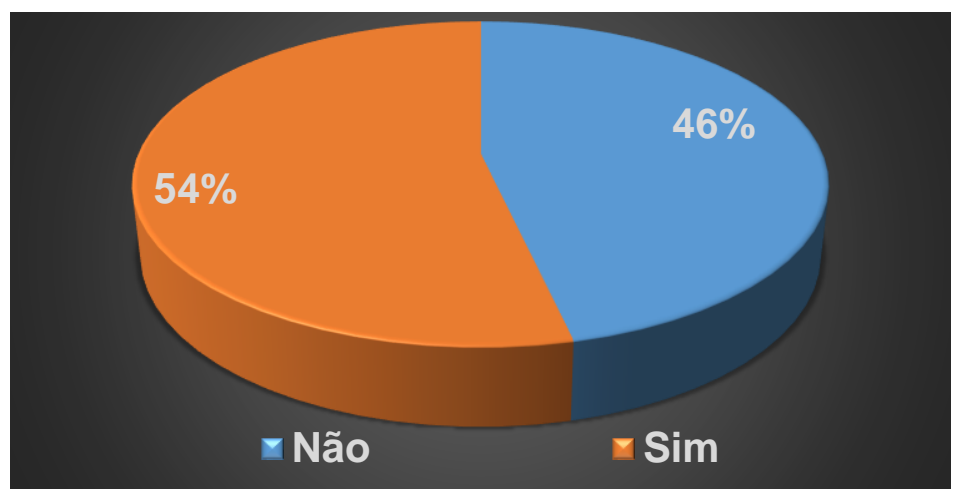

Figura 7: Tratamento de água.

Fonte: Dados da pesquisa (2018).

Quando perguntados a qual tipo de tratamento a água é submetida, observa-se que $42 \%$ utiliza hipoclorito de sódio - NaClO - que segundo informações é distribuído pela secretaria de saúde do município, mais precisamente no posto de saúde do bairro; $37 \%$ opta pela utilização apenas de sulfato de alumínio. É importante frisar que o sulfato de alumínio é utilizado para decantação de partículas mais densas presentes na água, por ação da gravidade e ajuste do $\mathrm{pH}$, logo, o mesmo é inapropriado para o combate de microrganismos como bactérias, protozoários, dentre outros. Cerca de 13\% dos residentes firma filtrar a água antes do consumo e por se tratar de uma água, visualmente, limpa após o procedimento de filtração, estes acreditam estar livre de microrganismos 
e por isso não precisar de nenhum outro tipo de tratamento. O percentual de $6 \%$ dos entrevistados utiliza água sanitária " $Q$ ' boa" na falta de hipoclorito, esta é utilizada por ser encontrada facilmente em comércios locais. Apenas $2 \%$ firmaram ferve a água antes de consumi-la, método melhor indicado por se tratar da eliminação de parasitas na água (Figura 8).

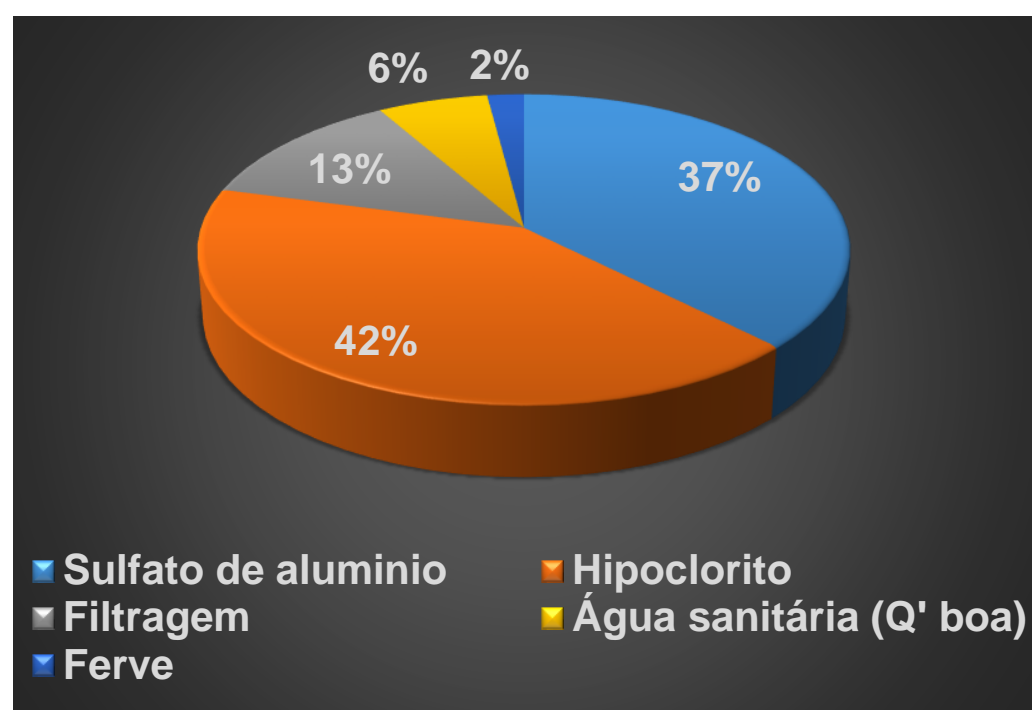

Figura 8: Tipos de tratamento da água.

Fonte: Dados da pesquisa (2018).

Em relação a higienização de frutas e legumes, $45 \%$ utilizam outros métodos de higienização, como a lavagem com limão e a imersão em solução de hipoclorito, $26 \%$ utiliza vinagre; $13 \%$ utiliza $\mathrm{NaClO}$ e $16 \%$ afirma utilizar água sanitária " $Q$ ' boa" para higienização. Os dados estão ilustrados na Figura 9. Fica claro que estes residentes não sabem ou desconhecem que $\mathrm{NaClO}$, água sanitária e hipoclorito, apresentam a mesma substância química $(\mathrm{NaClO})$ em sua composição.

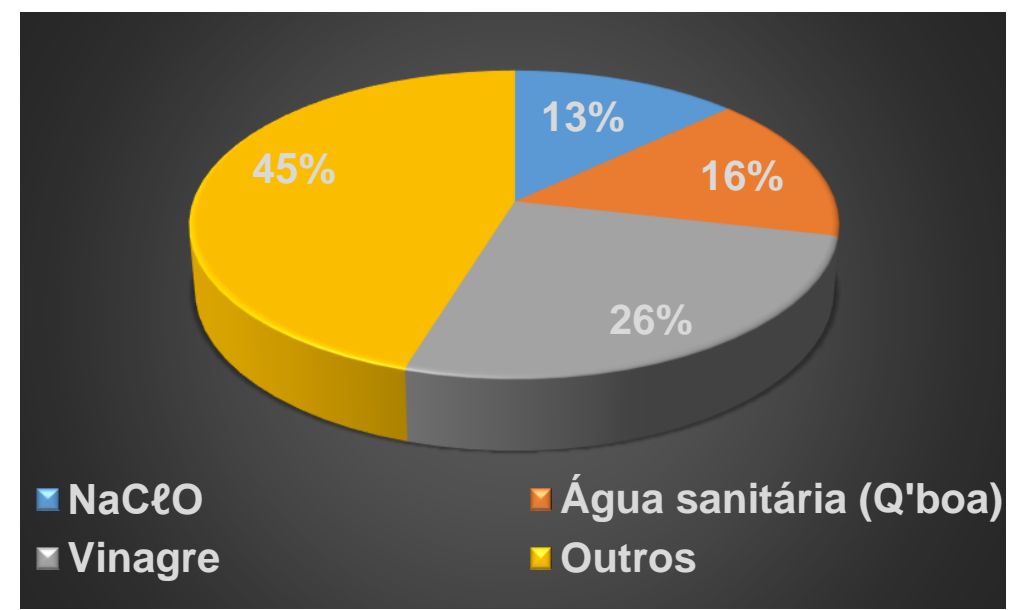

Figura 9: Higienização de frutas e legumes.

Fonte: Dados da pesquisa (2018). 
A maioria dos entrevistados, $95 \%$, relevou que utiliza a água do igarapé para algum fim, como: lavagem de roupas, louças, pontes, asseios de casa bem como para a higiene pessoal, porém, antes de utiliza-la realizam o processo de tratamento. Apenas $5 \%$ não utiliza água do igarapé para os fins mencionados anteriormente (Figura 10).

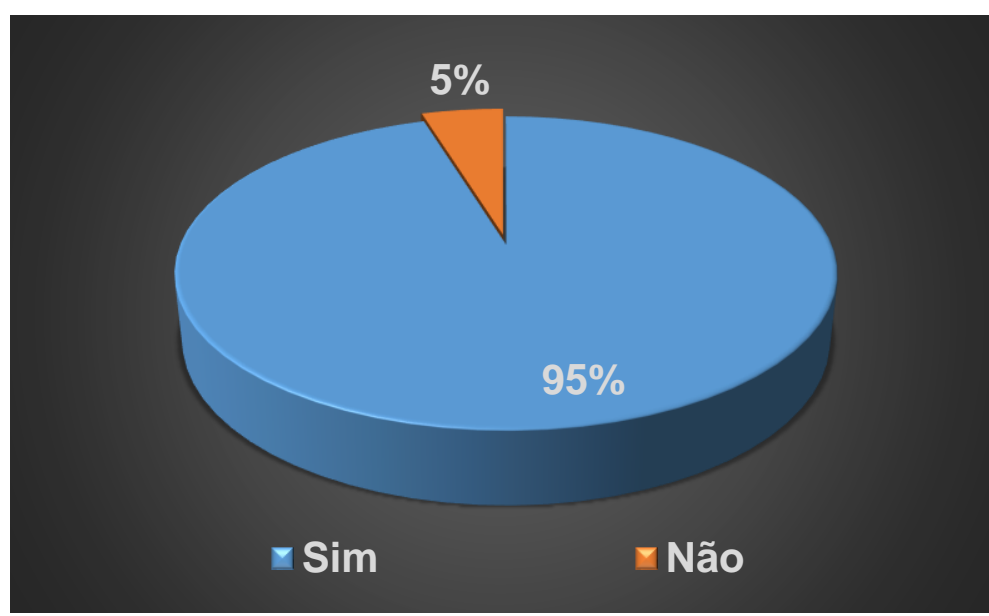

Figura 10: Utilização da água do igarapé para algum fim. Fonte: Dados da pesquisa (2018).

Foi possível mensurar que $11 \%$ dos entrevistados não faz o tratamento correto da água do igarapé e $89 \%$ faz o tratamento antes de consumi-la (Figura $11)$.

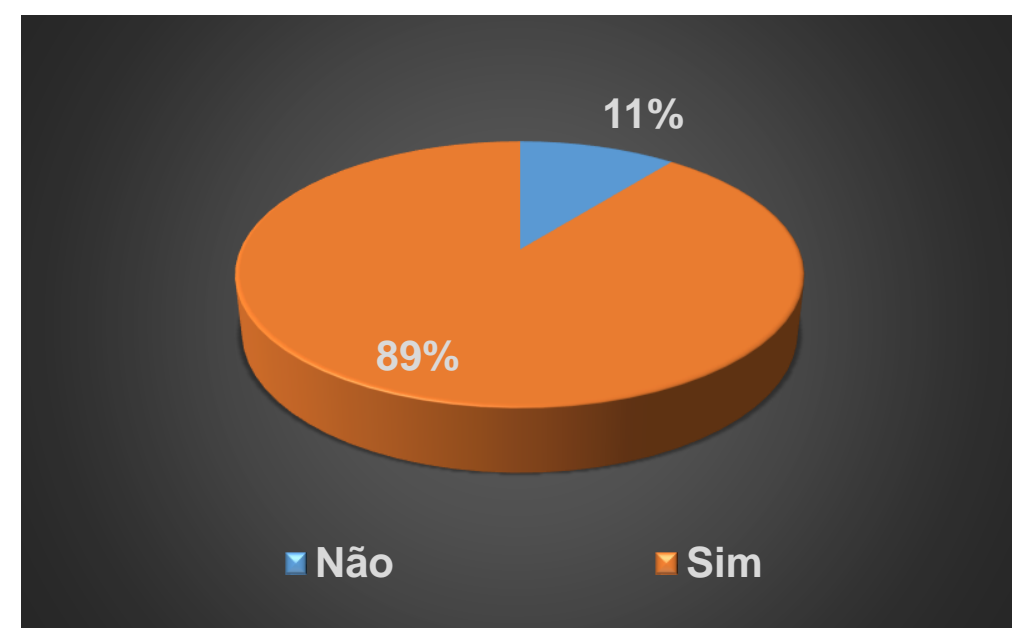

Figura 11: Tratamento da água do igarapé.

Fonte: Dados da pesquisa (2018). 
Alguns residentes relataram que fazem a captação da água do igarapé em baldes e o armazenamento é feito em caixas d'água (Figura 12a) e outros recipientes menores (Figura 12b), sendo que após os recipientes estarem cheios, a água contida nestes recebe os produtos de limpeza e tratamento de água, para assim, depois do processo concluído, esta água armazenada estará pronta para ser utilizada.

O tratamento de água é um longo processo de transformação pelo qual a água passa, até chegar à condição de uso adequado para o consumo humano, independente da função que ela terá. No entanto, as definições dos processos de tratamento da água dependem do lugar e da forma de como é captada, para a partir de então realizar a forma correta de tratamento.

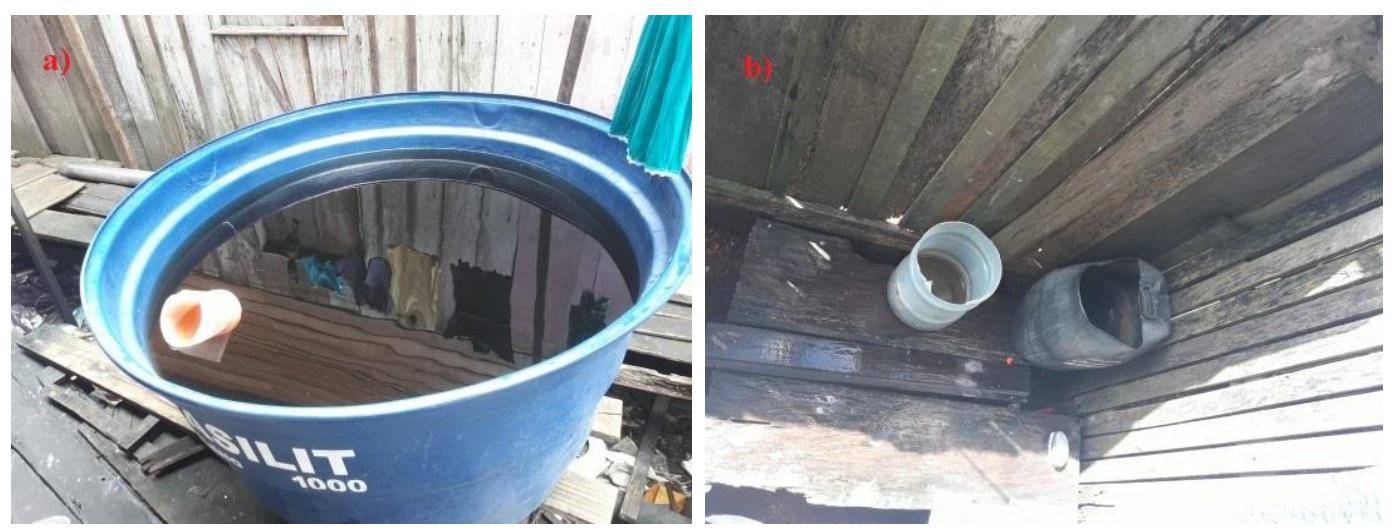

Figura 12: Armazenamento de água do igarapé. Fonte: Dados da pesquisa (2018).

Quando perguntados se há coleta de lixo, 82\% dos moradores afirmaram que sim e 18\% que não (Figura 13a). Para os que responderam que existe coleta de lixo, quando perguntados sobre a frequência em que é realizada, $26 \%$ dos moradores relataram que a coleta ocorre uma vez por semana, 33\% informaram que a coleta ocorre de duas; $33 \%$ que é feita três vezes e apenas $8 \%$ que a coleta é feita quatro vezes por semana (Figura 13b). No intervalo em que não há coleta, alguns moradores depositam seu lixo na rua, onde cachorros e gatos perfuram as sacolas espalhando lixo por toda a rua.

Moradores relataram que um dos fatores que dificulta o acesso do caminhão que faz a coleta de lixo é a péssima condição das ruas, pois a maioria delas foi aterrada pelos próprios moradores com "serragem" - pó de fragmentos ou lascas que saem da madeira que é serrada. Este material utilizado como aterramento absorve água facilmente transformando as ruas em verdadeiros atoleiros. Isso se intensifica nos períodos chuvosos e, também, em períodos de cheias do igarapé, dificultando assim o acesso dos caminhões coletores, por esse motivo alguns moradores tem que caminhar cerca de um quarteirão para depositar o lixo que será coletado. 

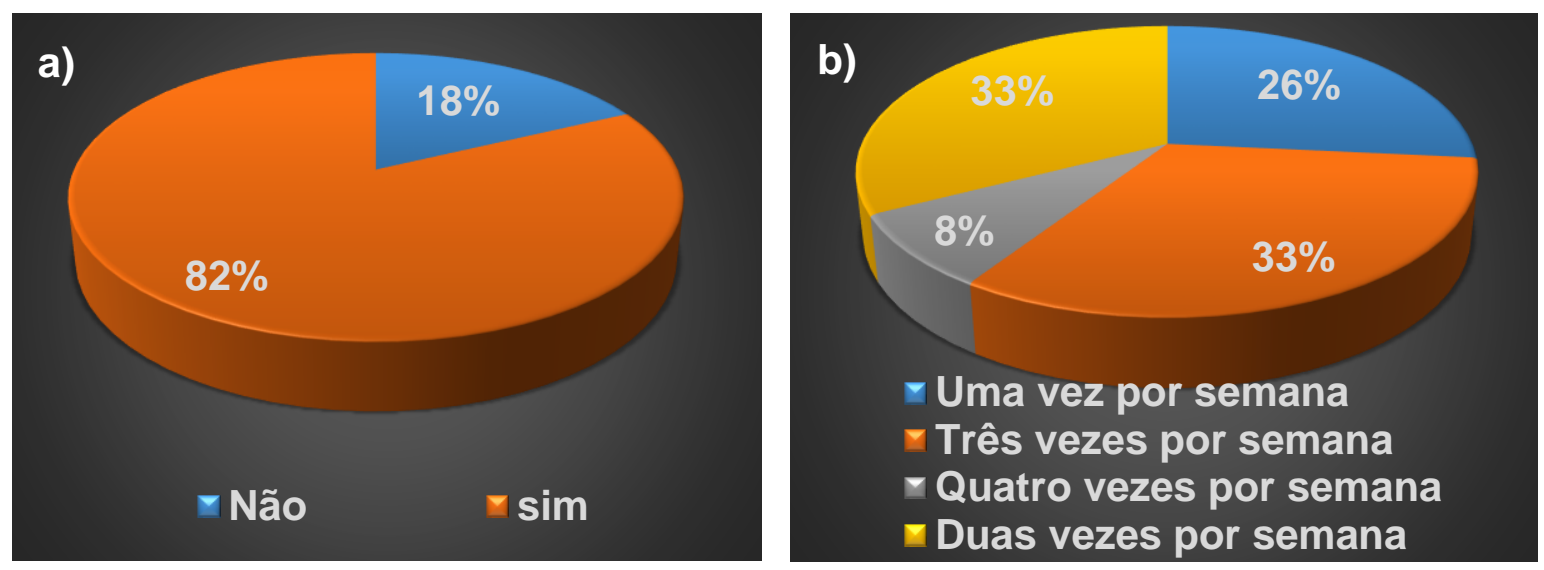

Figura 13: Coleta de lixo e frequência de coleta. Fonte: Dados da pesquisa (2018).

Constatou-se que $82 \%$, dos residentes destina o lixo para a coleta feita por caminhões vinculados a prefeitura do município, que terá como destino lixões localizados em terrenos, não adequados, distantes da cidade. Segundos relatos, a coleta de lixo não é satisfatória em virtude de condições estruturais das ruas que não permitem a entradas dos caminhões, principalmente em períodos chuvosos ou de lançantes do rio.

Outro destino para o lixo é o próprio igarapé Santa Cruz. Somado a isto, o igarapé ainda recebe dejetos humanos (fezes e urina), pois ao longo de sua margem há banheiros a céu aberto, além de óleo e dejetos dos banheiros oriundo das embarcações (Figura 14).

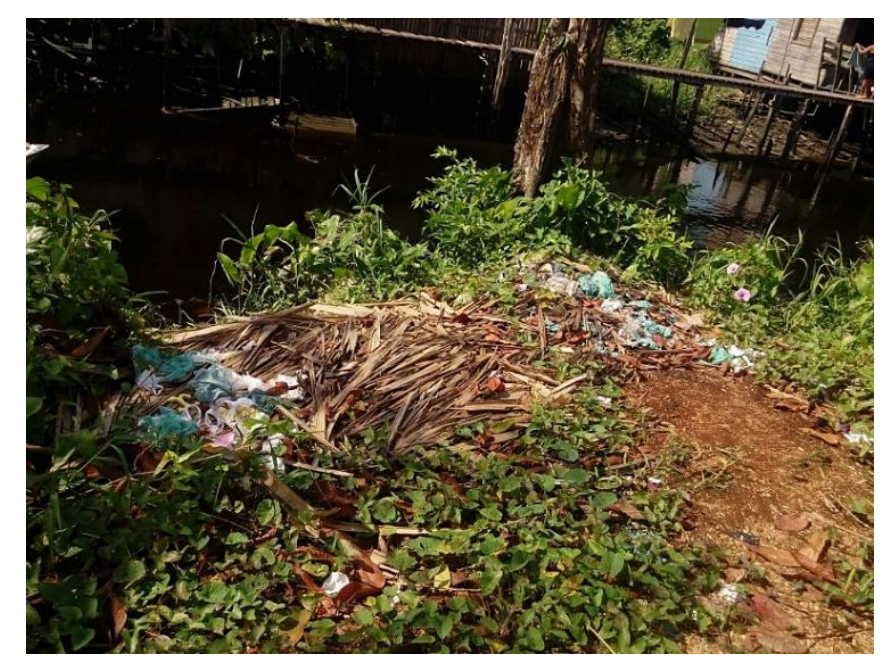

Figura 14: Lixo as margens do igarapé. Fonte: Dados da pesquisa (2018). 
Tal cenário corrobora os dados relacionados aos tipos de doenças investigadas na pesquisa (Figura 15). Observou-se que $5 \%$ relataram ter caso de amebíase; $18 \%$ afirmaram ter tido alguém em sua residência com caso de hepatite, $77 \%$ dos casos é destinada a outros tipos de doenças, como a dengue, febre tifoide e diarreias e verminoses. Essas doenças podem ocorrer por ingestão de água ou solo contaminado. O lixo tem grande importância na transmissão de doenças através, por exemplo, de vetores que nele encontram alimento, abrigo e condições adequadas para proliferação como os insetos. Há frequentemente a visita de agentes comunitários de saúde (ACS), com o objetivo voltado para a prevenção de doenças através de informações e orientações sobre cuidados à saúde.

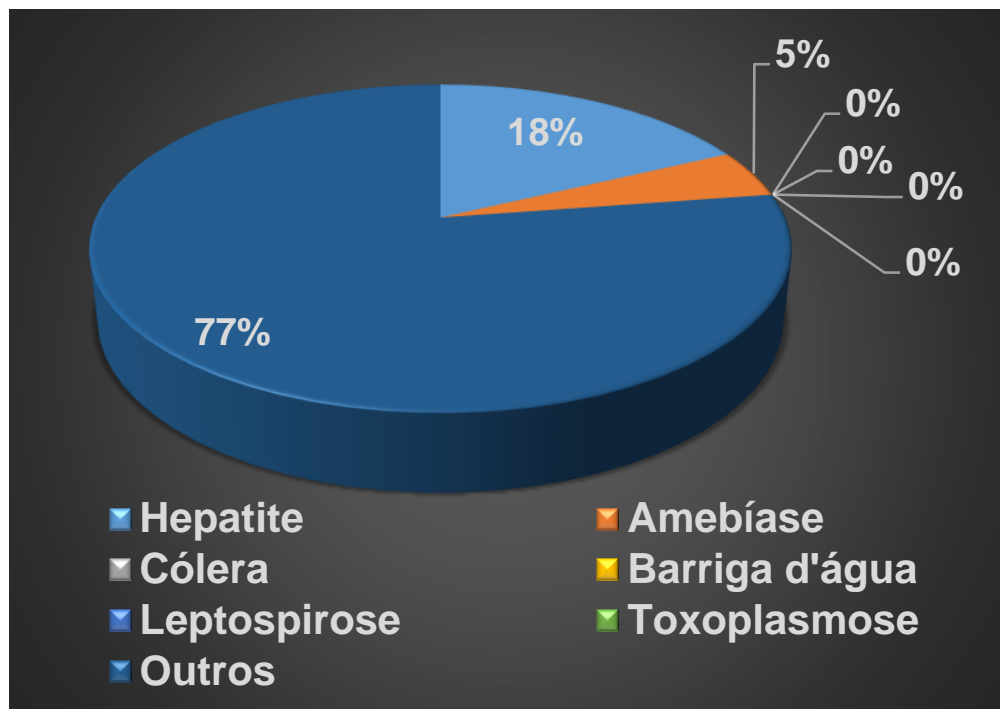

Figura 15: Casos de doenças.

Fonte: Dados da pesquisa (2018).

Quando perguntados se já tinham ouvido falar sobre preservação ambiental, $79 \%$ dos moradores afirmaram que sim e a maioria alegou ter ouvido em suas próprias casas através de seus familiares, em visitas de ASC ou até mesmo através das redes de comunicação. Ainda, outros responderam que ouviram em Escola e Centro de Referência da Assistência Social (CRAS).

Segundo dados do estudo, $60 \%$ dos moradores já ouviu de familiares sobre os principais cuidados com o ambiente natural.

Também foi investigado sobre 0 interesse dos residentes em participarem de reuniões, palestras e oficinas sobre educação ambiental. Logo, observou-se que $95 \%$ dos pesquisados demonstrou interesse. Portanto, é reconhecida a necessidade de promover mecanismos que possam alertar e orientar a população em prol de boas ações ao meio ambiente, uma vez que o referido assunto é imprescindível para manutenção da vida no planeta.

Quando perguntados sobre se participariam de palestras sobre descarte de resíduos sólidos, boas práticas de manipulação e higienização de alimentos, 
tratamento adequado de água, dentre outras observou-se que, 94\% participariam ou incentivariam seus filhos a participarem de palestras.

Segundo conversa informal com populares, poucas são as iniciativas de atividades como palestras, reuniões ou encontros que abordem esse tema e para eles seria muito importante saber a forma correta de separar e descartar o lixo.

\section{Conclusão}

O igarapé Santa Cruz, até meados da década de 1980, era pouco habitado e apresentava-se com sua mata ciliar sem grandes alterações, servia também de ligação marítima pela comunidade ribeirinha que trazia seus produtos agrícolas para vender na cidade e além disso proporcionava momentos de lazer a moradores que residiam em suas proximidades. Porém, com o forte incremento populacional na área, sua paisagem natural foi sofrendo os impactos da urbanização e, hoje, compõe um cenário totalmente adverso, onde o desmatamento foi decisivo nesta modificação, dando origem a estruturas habitacionais, tornando-o um igarapé praticamente sem mata ciliar, constituindose, desta forma, em um espaço quase totalmente urbano.

O crescimento populacional trouxe também o acúmulo de lixo, problema este que comprometeu suas águas, o que remete a saúde das pessoas que fazem uso da mesma. Como vimos acima, o esgoto e o lixo aliados à falta de infraestrutura de saneamento básico, tem destino certo, o leito do igarapé, tornando-se uma ameaça à própria vida humana e aos outros organismos que habitam suas águas.

Cuidar do meio ambiente está mais relacionado a utilizar o que temos, mas de forma racional, dando tempo para a natureza se recompor. Isso porque o consumo requer o uso da natureza e, desta forma, não há como deixá-la intocável. A utilização dos recursos naturais não pode comprometer quem vive hoje, nem as próximas gerações que habitarão nosso planeta. Diante deste cenário se faz necessário cuidados para manter o equilíbrio ambiental.

Constatou-se que o descarte de lixo no igarapé Santa Cruz é um grave problema, mas que com a união de todos da comunidade, Poder Público, Educação Ambiental, poderá ser resolvido através de mudanças de hábitos como: colocar o lixo na porta nos dias e horários determinados pela coleta municipal urbana para ser recolhido, praticar a coleta seletiva, fazer a reciclagem de materiais e outros. Assim será possível minimizar tais efeitos negativos e colaborar com a melhoria na qualidade de vida da comunidade e alcançar um ambiente sustentável para a atual e futuras gerações. 


\section{Agradecimentos}

Aos residentes ribeirinhos do Igarapé Santa Cruz, que possibilitaram o acesso aos dados da pesquisa. A coordenação do Campus Universitário do Marajó-Breves, pelo apoio logístico à pesquisa; à Universidade Federal do Pará, por tornar possível o desenvolvimento deste trabalho e a obtenção da graduação de um dos autores. A Pró-Reitoria de Extensão pelo apoio financeiro.

\section{Referências bibliografias}

BARBIERI, J. C. A educação ambiental e a gestão ambiental em cursos de graduação em administração: objetivos, desafios e propostas. RAP, Rio de Janeiro, v.38, n. 6, p.919-46, 2004.

BARBOSA, R. C. O papel da educação ambiental na escola. Disponível em: $<$ http://www.santecresiduos.com.br/artigos/papel edu.txt>. Acesso em: 15 nov. 2018.

CORSON, W. H. Manual Global de Ecologia: O que você pode fazer a respeito da crise do meio ambiente. 4aㅡ ed. São Paulo: Ed. Augustus, 2002.

CUNHA, B. P.; AUGUSTIN, S. Sustentabilidade ambiental: estudos jurídicos e sociais. $2^{\mathrm{a}}$ ed. Caxias do Sul: Ed. Educs, 2014.

DANTAS, A. O papel da habitação na Construção da Saúde Ambiental. Anais da Conferência Nacional de Saúde Ambiental, 1, 2009, Brasília, DF. 2009.

DIAS, G.F. Educação Ambiental: princípios e práticas. 9ª ed. São Paulo: Ed. Gaia, 2004, 541p.

GEWEHR, M. F. (2006). A explosão demográfica: causas e consequências. Disponível em:

http://www.egov.ufsc.br:8080/portal/sites/default/files/anexos/26524-26526-1PB.pdf>. Acessado em: 06 mai. 2019.

GOOGLE, 2019. Disponível em: <https://www.google.com/maps/place/Breves+$+\mathrm{PA},+68800-000 / @-1.6790838,-$

50.4906127,1492m/data=!3m1!1e3!4m5!3m4!1s0x9298384ef368bd59:0xd178f ee67d91ff17!8m2!3d-1.2936976!4d-50.5135589>. Acessado em: 04 abr. 2019.

GOUVEIA, N. Resíduos sólidos urbanos: impactos socioambientais e perspectiva de manejo sustentável com inclusão social. Ciência \& Saúde Coletiva, v.17, n.6, p.1503-1510, 2012.

JACQUARD, A. A explosão demográfica. Tradução de Paulo Herculano Marques Gouveis. São Paulo: Ed. Ática, 1998.

LEFF, E. Racionalidade ambiental. Rio de Janeiro: Civilização Brasileira, 2006. 
MARTINS, K. G. Expansão urbana desordenada e aumento dos riscos ambientais à saúde humana: o caso brasileiro. 2012. 65 f. Monografia. Programa de Bacharelado em Gestão Ambiental, Faculdade UNB Planaltina, Universidade de Brasília, Planaltina, 2012.

MENDONÇA, F. A. Geografia e meio ambiente. $8^{a}$ ed. São Paulo: Ed. Contexto, 2005.

MIRANDA, A. T. Urbanização do Brasil - Consequências e características das cidades.

Disponível

em:

$<$ https://educacao.uol.com.br/disciplinas/geografia/urbanizacao-do-brasil-

consequencias-e-caracteristicas-das-cidades.htm> Acessado em: 06 mai. 2019.

MUCELIN, C. A.; BELLINI, M. Lixo e impactos ambientais perceptíveis no ecossistema urbano. Sociedade \& Natureza, Uberlândia, v.20, n.1, p.111-124, 2008.

NETO, G. F.; BELTRAMIM, A. C.; RODRIGUES, C.; RHOLFS, D. B.; SALES, L. B. F.; ALONZO, H. R. A. Por um Movimento Nacional Ecossanitário. Anais da $1^{\text {a }}$ Conferência Nacional de Saúde Ambiental. Brasília, DF. 2009.

OLIVEIRA, A. U. Agricultura e Industria no Brasil. Campo-Território: Revista de Geografia Agraria, v.5, n.10, p.5-64, ago. 2009.

SCHAAN, D. P.; MARTINS, C.P. Muito além dos campos: arqueologia e história na Amazônia Marajoara. 1르 ed. Belém: Ed. Gknoronha, 2010.

PESSOA, G. P.; BRAGA, R. B. Educação Ambiental escolar e qualidade de vida: desafios e possibilidades. Revista Eletrônica do Mestrado em Educação Ambiental, v.24, p.143-155, 2010. Disponível em: < https://periodicos.furg.br/remea/article/view/3882/2319> Acessado em: 04, abr. 2019.

POLYCARPO, J. S. M.; DOS SANTOS JUNIOR, M. A.; MOURA, E. S.; MARINA BELTRAME, M.; BELTRAME, L. T. C. Doenças versus falta de saneamento no município de Pesqueira - PE. Disponível em: $<$ https://www.tratamentodeagua.com.br/artigo/doencas-falta-saneamento/> publicado em 01/08/2018. Acessado em: 06 mai. 2019.

REIS, S. R.; SANTOS, F. A. S. 2015. Princípios de educação ambiental para mudança de atitudes na escola de ensino fundamental sagrada família em Neopólis/SE.

Disponível em: https://eventos.set.edu.br/index.php/enfope/article/viewFile/1188/108>

Acessado em: 06 mai. 2019.

RIBEIRO, J. W.; ROOKE, J. M. S. Saneamento básico e sua relação com o meio ambiente e a saúde pública. 2010. 36 f. (TCC-Especialização) Curso de Especialização em Análise Ambiental, Universidade Federal de Juiz de Fora, Juiz de Fora - MG, 2010. Disponível em: $<$ http://www.ufjf.br/analiseambiental/files/2009/11/TCCsaneamentoeSa\%25C3\%25BAde.pdf>. Acessado em: 04/04/2019. 
SANTOS, F. A. S.; REIS, S. R.; TAVRES, J. A. V. (2012). Educação ambiental e sua importância para a sociedade em risco: reflexão no ensino formal. Disponível em: <http://geces.com.br/simposio/anais/anais-2012/Anais-133146.pdf>. Acessado em: 04/04/2019.

SANTOS, A. B. A.; LUIZ, A.; CORREIA, B; BEQUIMAM, I.; TRINDADE, M.; SANTOS, R. (2010). Resíduos sólidos: uma revisão bibliográfica. Disponível em: $<$ http://www.catolica-

to.edu.br/portal/portal/downloads/docs gestaoambiental/projetos2010-2/4-

periodo/Residuos solidos uma revisao bibliografica.pdf> Acessado em: 06 mai. 2019.

SCARLATO, F.C.; PONTIN, J.A. O ambiente urbano. 2aㅡ. ed. São Paulo: Ed. Saraiva, 2001.

THIOLLENT, M. A. Metodologia Participativa e sua Aplicação em Projetos de Extensão Universitária. In: Metodologia e Experiências em Projetos de Extensão. Niterói: 2000, p. 19-28.

VALENTE, G. S. (2017). Sistema de abastecimento de água do Município de Breves-PA.

$<$ http://geoobras.tcm.pa.gov.br/Cidadao/Licitacao/Download?unidadegestora=1 8001\&id=L1227 17242\&extensao=pdf $>$. Acessado em: 06/05/2019. 